\title{
Compliance packaging for over-the-counter drug products
}

\author{
Susanna Weiss
}

Received: 6 December 2007 / Accepted: 6 October 2008 / Published online: 20 January 2009

(C) The Author(s) 2009. This article is published with open access at Springerlink.com

\begin{abstract}
Background In view of the serious health risks and high costs to the health-care system of misuse and abuse of overthe-counter (OTC) analgesics, this article describes a rationale and prototype for new safety or compliance packaging for OTC drug products that are sold in pill form (e.g., tablets, caplets and gelcaps) inside blister packs. The proposed packaging is not simply promoting the use of blister packs for pills; that utility is already well known. It is an integrated system in which blister packs of pills can, themselves, be packaged, labeled and sold, offering a dosedirected unit-of-use design with enhanced warnings and directions to help prevent consumers from taking more than the instructed dose of pill-form medicines.

Method Literature and information searches were conducted in publicly available databases and websites to (1) assess safety problems (serious adverse events and fatalities) associated with OTC analgesics and (2) determine public perceptions and knowledge about their use.

Results Each year in the US, there are an estimated 100,000 hospitalizations and 16,500 deaths due to NSAID overdosing, and 26,000 hospitalizations and 1,600 acute liver
\end{abstract}

The term "compliance packaging" is used for this prototype because it is packaging designed to increase consumer compliance and to distinguish it from the more commonly known child-proof safety packaging or tamper-evident packaging.

S. Weiss $(\bowtie)$

Division of Clinical Research, Office of Strategic Planning and Assessment, National Institute of Allergy and Infectious Diseases, National Institutes of Health,

6700B Rockledge Drive, Rm. 1106, MSC 7609,

Bethesda, MD 20892-7609, USA

e-mail: Weisssu@niaid.nih.gov failure cases due to acetaminophen poisoning. Many adults take more than the recommended dose and in some cases use multiple products containing acetaminophen and ibuprofen. Risk factors, such as alcohol use or pre-existing liver disease, exacerbate problems associated with acetaminophen misuse and abuse. In pediatric cases, dosing errors are often related to confusion over different product formulations, dosing strengths, and the use of inappropriate dosing devices. Consumers are often unaware of the active ingredients in, and correct doses of, drugs they are taking; they underestimate the risks associated with misuse of OTC medicines, and they frequently discard the packaging on which the drug's directions, warnings and dosing instructions are located.

Conclusion Optimal compliance packaging should (1) keep the instructions, warnings and dosing directions attached to the blister card of pills at all times, thus avoiding the problem of cartons and package inserts being thrown away once the package is opened; (2) increase the surface area of the packaging, without adding bulk, to provide space for the use of larger font sizes and enhanced directions and warnings that are more conspicuous, explicit and memorable; (3) organize the pills into logical, unit-of-use (per-dose maximum and perday maximum) sets or rows; (4) limit the number of pills in a unit-of-use package to coincide with the instructed maximum dose and maximum days of use for a specific product.

Keywords Dose compliance - OTC drugs · Packaging · Labeling $\cdot$ Warnings $\cdot$ Directions

\section{Introduction}

Acetaminophen (also known as paracetamol or APAP) and non-steroidal anti-inflammatory drugs (NSAIDs), such as 
ibuprofen, are well-known analgesics available over the counter (OTC) for relief of minor aches and pains and for temporary reduction of fever. Estimates of acetaminophen and NSAID use vary, but they indicate ubiquitous and frequent use (Amar and Schiff 2007; National Consumers League 2003). According to the Consumer Healthcare Products Association (CHPA 2002), 160 million American adults rely on OTC analgesics to relieve pain or reduce fever in any given week. In addition to their role as singleingredient pain relievers, acetaminophen or ibuprofen is present in numerous combination OTC products that are used for cough-cold and allergy-sinus relief.

However, particularly important safety concerns (organspecific risks) apply to these analgesics if they are taken in excess of the recommended dose, or for too many days, or in contradiction to the labeled warnings. Yet research reveals that $44 \%$ of US adults who take OTC pain relievers admit to ignoring label warnings and exceeding the recommended dose (National Consumers League 2003), and only about $2 \%$ of adults actually know the correct daily dose of popular analgesics that they take on a regular basis (Stumpf et al. 2007).

The compliance packaging described in this article utilizes evidence-based methods to package and label OTC drugs in order to enhance consumer assimilation of dosing directions and warning information, and maximize compliance with the label instructions. The prototype increases the surface area of the packaging to accommodate larger, more conspicuous and explicit warnings and dosing directions without adding bulk. It also increases the probability that the drug's instructions will remain attached to the drug product, thus enhancing the communication of crucial information that might otherwise be discarded or ignored by consumers. The objective is to provide more functional unit-of-use packaging that facilitates the noticing, reading and keeping of drug instructions. Any additional packaging cost will, hopefully, be outweighed by the benefit of saving lives and health-care dollars.

\section{Use, misuse and abuse of OTC analgesics}

Acetaminophen hepatoxicity

A population-based study by Bower et al. (2007) suggests that approximately 1,600 acute liver failure (ALF) cases occur in the US each year, with acetaminophen-related ALF being the most common etiology. Larson (2007) reports that APAP was responsible for $51 \%$ of ALF cases in the US in 2003. In one prospective study of 308 ALF cases, over two-thirds of the consumers took more than $4 \mathrm{~g}$ of acetaminophen per day, and in $32 \%$ of those cases consumers took more than $10 \mathrm{~g}$ per day (Ostapowicz et al. 2002). Over $4 \mathrm{~g}$ per day of acetaminophen for long periods is considered abuse (Abbott and Fraser 1998).

According to Nourjah et al. (2006), APAP-associated overdoses (unintentional and intentional) accounted for about 56,000 emergency department visits each year between 1993 and 1999, about 26,000 hospitalizations each year between 1990 and 1999, and an average of 458 deaths each year in 1996, 1997 and 1998. In 1995, Bond and Novak estimated the annual health-care costs associated with all US intentional adult and adolescent acetaminophen self-poisoning to be nearly $\$ 87$ million.

The extent of intentional versus unintentional overdosing with acetaminophen is not clear. Ostapowicz et al. (2002) report that $68(57 \%)$ of the 308 APAP-associated ALF cases in their study were deemed unintentional (nonsuicidal) overdoses. Other analyses have estimated that between $8 \%-26 \%$ of APAP-related overdoses are unintentional (Nourjah et al. 2006), and between $6 \%$ and 30\% of unintentional overdoses are due to therapeutic misuse (Nourjah et al. 2006; Gyamlani and Parikh 2002; Schiodt et al. 1997). Hepatoxicity can occur even within the maximum daily recommended dose of $4 \mathrm{~g}$ (Eriksson et al. 1992; Moling et al. 2006; Bolesta and Haber 2002; Kurtovic and Riordan 2003), and is especially likely to occur when therapeutic doses are taken under certain conditions, such as ingesting alcohol or fasting ${ }^{1}$ (Larson 2007; Ostapowicz et al. 2002), though it may occur within the therapeutic dose even in the absence of malnutrition or alcohol use or abuse (Bonkovsky et al. 1994).

The US Food and Drug Administration and acetaminophen

In September 2002, the US Food and Drug Administration (FDA) convened a Nonprescription Drug Advisory Committee (NDAC) meeting to consider safety issues concerning OTC analgesics, including the potential for hepatoxicity associated with acetaminophen. The NDAC heard from William Lee, M.D., University of Texas Southwestern Medical Center, Dallas, that there are an estimated 1,000 to 2,000 acute liver failure cases in the US each year, nearly a third of which are fatal.

Hepatoxicity reports received through FDA's adverse event reporting system (AERS) between January 1998 and July 2001 showed that acetaminophen overdoses were associated with large numbers of emergency department

\footnotetext{
${ }^{1}$ FDA guidelines published in 2004 note that the risk of liver damage increases with consumption of three or more alcoholic drinks a day (http://www.fda.gov/cder/drug/analgesics/default.htm, accessed 5/18/ 2008). Dart (2001) estimates that, since $22 \%$ of US adults use acetaminophen each week and $5 \%$ to $10 \%$ of the population abuses alcohol, the health-care implications of serious adverse interactions are considerable.
} 
and hospital admissions and were related to an estimated 100 deaths each year (Federal Register 2006). Moore et al.'s (2007) analysis of AERS data from 1998 to 2005 concluded that acetaminophen ranked fifth as the most frequent suspect drug for cases involving death or serious nonfatal outcomes.

The FDA has concluded that the following factors lead to OTC-drug induced hepatoxicity: (1) adults taking more than the recommended dose of acetaminophen, and in some cases using multiple products containing acetaminophen; (2) risk factors such as alcohol use or pre-existing liver disease; (3) errors related to confusion over different product formulations, dosing strengths and the use of inappropriate dosing devices in pediatric cases (Federal Register 2006).

International problems with acetaminophen

Acetaminophen misuse and abuse also appear to be serious problems in the United Kingdom (UK) and Canada. Hawkins et al. (2007) note that paracetamol (the UK name for acetaminophen) is the most common drug taken in overdose in the UK, accounting for $48 \%$ of poisoning admissions to hospital, and is involved in an estimated 100200 deaths per year. Turvill et al. (2000) report that paracetamol is the most common cause of intentional selfharm in the UK, with an estimated 70,000 cases per year, and represents a heavy burden to emergency, medical, and psychiatric services. Myers et al. (2007) examined acetaminophen overdose rates in Canada between 1997 and 2002 and found an adjusted incidence of 35.1 per 100,000 population in 2002 , with $69 \%$ of cases being intentional, and $25 \%$ being unintentional.

Misuse and abuse of ibuprofen and other NSAIDs

The use of non-steroidal anti-inflammatory drugs (NSAIDs) is also widespread, and overdosing is common. Amar and Schiff (2007) report that NSAIDs are estimated to result in over 100,000 hospitalizations per year, at a cost of more than $\$ 2$ billion, and are responsible for 16,500 deaths annually in the US. Ibuprofen overdosing, although often asymptomatic or only moderately symptomatic, can result in serious toxicity complicated by metabolic acidosis, renal insufficiency and/or renal failure necessitating prolonged dialysis (see Wood et al. 2006; Volans et al. 2003; Kim et al. 1995; Zuckerman and Uy 1995; Le et al. 1994; Downie et al. 1993; Halpern et al. 1993).

The FDA's 2002 NDAC heard the results of a National Kidney Foundation study (initiated in 1995) that examined 556 articles published in the medical literature about analgesic-related nephrotoxicity and concluded that there should be explicit label warnings about potential renal risks of consuming OTC NSAIDs (Federal Register 2006). The FDA analyzed AERS cases from 1984 to 1999 involving OTC NSAIDs and found that out of 121 cases of renal failure, 94 involved ibuprofen-56 required hospitalization, 9 needed dialysis and 9 died. Renal failure occurred within less than 7 days of exposure to the drug; 14 ibuprofen cases were within the pediatric age group (Federal Register 2006).

\section{Public knowledge about OTC analgesics}

Although in the UK the incidence of paracetamol poisoning seems to be related to its availability rather than ignorance of its complications (Hawton et al. 1995), in the US there appears to be little understanding and/or acceptance among the general public that analgesic misuse or abuse can cause real and lasting damage. Two large US national surveys totaling 9,062 respondents-a survey conducted in SeptemberOctober 1997 by Roper Starch Worldwide for the American Gastroenterological Association (AGA), ${ }^{2}$ and a survey conducted in December 2002 by Harris Interactive ${ }^{\circledR}$ for the National Consumers League (NCL)-have revealed some disturbing consumer behaviors and opinions associated with OTC analgesics (American Gastroenterological Association 1998; National Consumers League 2003).

In the Roper survey, $60 \%$ of the exclusive OTC-NSAID users said they were not aware they were at risk of side effects from NSAIDs; $29 \%$ said they did not believe they were at risk of side effects from NSAIDs; $46 \%$ thought OTC-NSAIDs were safer than prescription NSAIDs; $26 \%$ said they used more than the recommended dose on the product label; $22 \%$ said they thought warning symptoms would precede any NSAID-induced complications.

In the Harris survey (projected to represent 175 million US adults), $84 \%$ reported using an OTC pain reliever in the last year and $15 \%$ reported daily use. Alarmingly, $44 \%$ said they consumed more than the recommended dose on the product label; $50 \%$ said they were not concerned about potential side effects; $45 \%$ said it is important to control pain regardless of risk; $45 \%$ said it is safe to take an OTC pain reliever while also taking another OTC cold or flu medication; 34\% said it is safe to take an OTC pain reliever while taking a prescription medication; almost $20 \%$ said it is safe to take an OTC pain reliever while drinking alcohol; $30 \%$ believed there was less risk with the use of OTC analgesics than with prescription analgesics; only $16 \%$ reported reading the entire product label.

The responses of arthritis sufferers and heavy drinkersthose with increased risk for side effects due to prolonged

\footnotetext{
${ }^{2}$ The summary reported here is extracted from an article by Wilcox et al. (2005).
} 
use or overuse-were particularly worrying: nearly $60 \%$ of heavy drinkers (defined as those who consume three or more drinks a day, five or more times a month) said they were not concerned about side effects, and $65 \%$ reported consuming alcohol the same day they took OTC pain medication.

Problems associated with OTC analgesic misuse and abuse are compounded by the fact that few consumers accurately recall correct dosing instructions. Stumpf et al. (2007) found that, while nearly $80 \%$ of their 104 subjects reported using a drug product containing acetaminophen during the past 6 months, and while $18.3 \%$ were taking an acetaminophen-containing medicine at least once a day, nearly $70 \%$ of the patients underestimated the maximum recommended daily dose of regular-strength acetaminophen. Only 2 patients (2\%) knew the correct dose of regular-strength acetaminophen, only 3 knew the correct dose of extra-strength acetaminophen, and 28 patients were not sure of the maximum dose of either formulation of acetaminophen.

Risks to the elderly are especially high

Elderly consumers are especially at risk for health problems associated with large single doses or prolonged smaller doses of analgesics (Francis et al. 2005), because they are the largest consumers of prescription and OTC medicines in general, and they take more medicines for chronic pain than do other age groups. Furthermore, the knowledge gap is highest among the elderly vis-à-vis the types of multiple pain medications they may be taking and the dosing instructions for those drugs; they are more vulnerable to adverse drug effects in general and are more prone to developing digestive tract complications, and they are twice as likely to underestimate the risks associated with prolonged analgesic misuse (American Gastroenterological Association 1998).

Teenagers and young adults

Equally worrying are the knowledge and beliefs of teenagers in relation to OTC analgesics, especially since acetaminophen is often taken in overdose by adolescents during suicidal gestures. Myers et al. (1992) surveyed 169 high school students and found that $22 \%$ of the sample underestimated the dose of acetaminophen necessary to cause harm, $40.5 \%$ underestimated the potential lethality of acetaminophen, and $17 \%$ did not believe one could ingest enough to cause death. Huott and Storrow (1997) surveyed adolescents aged 13-18 about OTC medicines that are regularly found at home and revealed limited understanding of which ones can be lethal when taken in overdose (aspirin $63 \%$, APAP $57 \%$, antihistamines $46 \%$, iron $24 \%$, camphor
$22 \%$, methyl salicylate $21 \%$, and bismuth subsalicylate $19 \%)$.

Surprisingly, however, while adolescents may have limited general knowledge about the toxicity and lethality of OTC drugs, one study found that $75 \%$ of a sample of 876 teens and young adults (aged 14-27) reported that they do read OTC drug labels and package inserts-especially when purchasing medicines to treat symptoms requiring immediate attention (such as stomach pain, colds/flu or joint pain)-in order to learn about dosing instructions, side effects, symptoms treated by the medicine and ingredients (Nabors et al. 2004). It is therefore crucial for OTC drug labeling to be written and presented in ways that are cognitively accessible to adolescents and young adults, and for warnings to be conspicuous and memorable, not least because this age group accounts for the majority of intentional OTC acetaminophen overdoses.

\section{NDAC recommendations and the FDA's 2006 proposed rule for OTC analgesics}

OTC labeling The FDA's 2002 NDAC concluded that labeling is a major factor in promoting the safe and effective use of OTC analgesics. The committee was concerned that consumers do not read labels adequately and are often unaware of the active ingredients in medicines they are taking. Doubts were expressed about the ability to communicate meaningful information in the confines of a small package label, especially to the elderly (Federal Register 2006).

Package size and configuration limitations The FDA announced in its 2006 Proposed Rule for OTC analgesics that it is seeking comments on package size and package configuration limitations as a mechanism to increase safe use of OTC analgesics by reducing unintentional and intentional overdose (Federal Register 2006).

\section{Package size and configuration are particularly important for OTC analgesic products}

To decrease intentional overdosing it may be helpful to impede impulsive behavior, such as swallowing a handful of pills, by: (1) selling blister packs rather than bottles of pills, (2) limiting the maximum number of tablets in each blister pack and (3) limiting the number of pills that can be purchased at one time. Hawton et al. (1996) found that 33 out of 80 patients $(41 \%)$ had seriously contemplated taking an overdose for less than $1 \mathrm{~h}$, and patients who took more than 25 tablets were more likely to have taken loose pills 
than pills from blister packs. Turvill et al. (2000) suggest that blister packs sold in limited quantities offer hurdles to impulsive suicidal actions by reducing availability and adding time needed to ingest a toxic quantity of pills, which might allow for reflection and a change of mind. Chan (2000) reports that blister packs have been associated with fewer tablets being ingested in paracetamol self-poisonings in Hong Kong. To help prevent unintentional overdosing, the pills can be organized in a per-dose, per-day, XX-day system (matching instructions in the "Drug Facts" label) to help consumers keep track of the number of doses consumed, and warnings should be made far more conspicuous and explicit.

\section{Package size and configuration restrictions: The UK experience}

In September 1998, the UK introduced legislation limiting the maximum pack size of non-effervescent tablets and capsules containing aspirin (acetylsalicylic acid) or paracetamol (acetaminophen) that can be sold or supplied from outlets other than registered pharmacies to $16 \times 500 \mathrm{mg}$ tablets or capsules, and from registered pharmacies to $32 \times$ $500 \mathrm{mg}$ tablets or capsules. If a consumer can show a bona fide need for larger quantities (e.g., an arthritis sufferer), the pharmacist has the discretion to permit the purchase of up to 100 tablets (which would actually be 96 tablets in three packs of 32 tablets). Paracetamol pack-size restrictions were introduced in Ireland in October 2001, where packs are limited to 12 tablets, and only one pack can be sold per transaction.

A considerable amount of research and discussion has taken place since 1998 to assess the effects of this legislation, with findings being mostly positive. Hawkins et al. (2007) reviewed 17 studies and concluded that the legislation has predominantly reduced mortality rates, admissions to liver units/liver transplants, hospital admissions and the severity of paracetamol overdoses since 1998, although more long-term studies are needed to fully assess the impact of the legislation. ${ }^{3}$

Before-and-after studies by Hawton et al. in 2001 and 2004, evaluating data from September 1996 to September 1999 and September 1993 to September 2002, respectively, concluded that the pack-size restrictions have been beneficial-suicidal deaths from paracetamol and salicylates were reduced by $22 \%$ in the year after the change in legislation (September 1998), and this reduction persisted in the next 2

\footnotetext{
${ }^{3}$ Although Morgan et al. (2005) reported that paracetamol-only deaths in England and Wales decreased from about 4.5 to 2.8 per million between 1997 and 1999, and from about 3.1 to 2.2 per million between 2001 and 2002, they concluded that the contribution of the 1998 regulations to this decline is not clear.
}

years. Liver unit admissions and liver transplants for paracetamol-induced hepatotoxicity were reduced by about $30 \%$ in the 4 years after the legislation. Numbers of paracetamol and salicylate tablets in non-fatal overdoses were also reduced in the 3 years after the legislation. Large overdoses were reduced by $20 \%$ for paracetamol and by $39 \%$ for salicylates in the 2 nd and 3 rd years after the legislation.

Prince et al. (2000) analyzed data from admissions to a liver unit in a northern England urban hospital and patients registered in the UK for liver transplantation for paracetamol hepatoxicity between October 1995 and December 1999. Results indicated substantial reductions $(p<0.02)^{4}$ in the frequency of paracetamol hepatoxicity locally and nationally after legislation went into effect in September 1998, and these reductions were not explained by changes in referral patterns or use of $\mathrm{N}$-acetylcysteine.

Turvill et al. (2000) found that for the 3 years preceding the legislation, the number of paracetamol overdoses presenting at a large London hospital was consistent. In the year following the compulsory introduction of blister packs, there was a $21 \%$ reduction in all paracetamol overdoses and a $64 \%$ reduction in severe overdoses.

Donohoe et al. (2006) examined deliberate paracetamol overdoses reported during two 24-month periods before and after the legislative changes in Ireland in October 2001. They concluded that the number of tablets taken in these overdoses fell significantly after October 2001: fewer cases involved 12-24 tablets and fewer cases involved more than 24 tablets.

\section{Counter-arguments from the UK}

Bateman et al. (2006) analyzed routine death and hospital discharge data for the entire Scottish population from 1995 to 2004 and concluded that the legislation has not reduced mortality or proportional use of paracetamol in overdose deaths, both of which appear to have increased in Scotland since pack-size limitations were introduced. This anomaly, however, might be explained by the following: (1) overdose rates in Scotland have traditionally been higher than in the rest of the UK and (2) the majority of the paracetamolassociated deaths from 1995-2004 were due to prescription co-proxamol rather than OTC paracetamol.

\footnotetext{
${ }^{4}$ In the 3 years prior to September 1998, the annual rate of referrals to the Freeman was falling by an average of 4.5 patients per year. It fell by ten patients per year after the legislation was introduced. Also, even though the number of referrals to the UK transplantation registry had been increasing annually in the 3 years prior to September 1998 by an average of 7.5 patients per year, the median number of monthly referrals fell from 3.5 to $2(\mathrm{p}<0.02)$ after the legislation was introduced.
} 
Sheen et al. (2002) have reported that while the total mass of paracetamol and aspirin sold between 1998 and 2000 fell, that of ibuprofen increased, although the increased ibuprofen sales did not translate into higher mortality rates.

Papadopoulos (2004) analyzed mortality statistics for England and Wales and concluded that while suicide attempts using paracetamol and admissions to liver units may have decreased following the packaging legislation, deaths from suicide overall did not decrease, suggesting that people who are seriously suicidal simply turn to other methods of suicide instead of pills. Similarly, Jowett (2004) warns that selfpoisoners will choose alternative drugs (predominantly antidepressant and anti-psychotic sedatives) and drug "cocktails," leaving the problem of drug-overdose suicides unresolved by the paracetamol pack-size legislation.

Although those bent on suicide may seek alternative methods no matter what kind of legislation is imposed, this should not diminish or negate the positive results that have accrued from the pack-size legislation vis-à-vis both intentional and unintentional overdoses. Even if such legislation cannot provide a complete answer to druginduced suicides, it has still shown that it can save hundreds of lives annually that would otherwise have been lost if no such legislation had been in place. The fact remains that any reduction in lives lost from acetaminophen and NSAID overdoses is a beneficial outcome. Ultimately, as Greene et al. (2006) point out, pack-size legislation can only work if it is enforced. Their study revealed that $46 \%$ of patients who had ingested a potentially toxic dose of paracetamol obtained the tablets from pharmacy and non-pharmacy outlets in a manner contravening the legislation.

\section{The problem to be solved by this prototype compliance packaging}

The US Food and Drug Administration requires that important information pertaining to each OTC drug product be printed in a specific format in what is called a "Drug Facts" label, and this "Drug Facts" label must be printed on the outer packaging of the drug product, so that consumers can read important information about the medication prior to purchasing the product. The "Drug Facts" label includes information about the drug's active ingredient(s), its uses, warnings (e.g., allergy alert(s), contraindications, side effects, when to use or not to use the drug, when and why to ask a doctor or pharmacist about certain medical issues related to taking the drug, what to expect when using the product, when to stop using the product, and special pregnancy and breast-feeding warnings), directions for taking the drug product, information about storing the product and a list of the drug's inactive ingredients.
However, one of the main concerns about the packaging of OTC drugs is the fact that important directions and warnings for taking a medicine are often printed only on the outer packaging, e.g., the carton in which the product is sold, but after purchase, consumers open up the package, remove the pills that are inside, and frequently throw the carton away-hence the instructions and warnings are discarded as well, and consumers no longer have the important warnings and dosing directions in front of them each time they use the drug product. Cheatham and Wogalter (2002), for example, found that study participants said they would save the OTC medication box only about $15 \%$ of the time. In addition, more subjects reported reading information about the drug a higher percentage of the time before $(M=63.5 \%)$ rather than after $(M=27.4 \%)$ opening and using the OTC drug for the first time.

The compliance packaging described here (Figs. 1 and 2) solves this problem by incorporating the blister pack of pills directly into a hinged-card system that remains attached to the blister pack of pills for the duration of their use, thus keeping the "Drug Facts" label, which contains the dosing directions, warnings, etc., with the pills at all times. The hinged card opens like a book, and the blister pack of pills is incorporated into the right-hand leaf of the card to hold it in place. When the product is sold, the hinged card would be folded closed and covered with a clear plastic film to prevent tampering, but still leave all the Drug Facts labeling visible and readable. It would be stocked on hanging pegs in the OTC pharmacy area.

\section{The need for more conspicuous warnings and explicit information about risks}

The hinged-card arrangement described here (1) provides increased surface space on which to print the "Drug Facts" label in a larger font size than would be possible on a regular carton; (2) provides space on which to print enhanced, more salient warnings and directions to help emphasize and explain to consumers why it is important to follow the dosing directions, and what can happen when the directions are ignored; (3) keeps the enhanced consumer information-the additional, more conspicuous warnings and dosing instructions-attached to the pills so they will NOT be discarded like a carton or an inserted instructions sheet might be.

Accessible and salient Research indicates that a product warning is far more effective when it is easily accessible and when users must physically interact with it during product use (Wogalter and Young 1994; Lesch in Wogalter 2006). Studies with medication and non-medication products show that placement of the warning on the product 
Fig. 1 The outside panels of the prototype compliance packaging

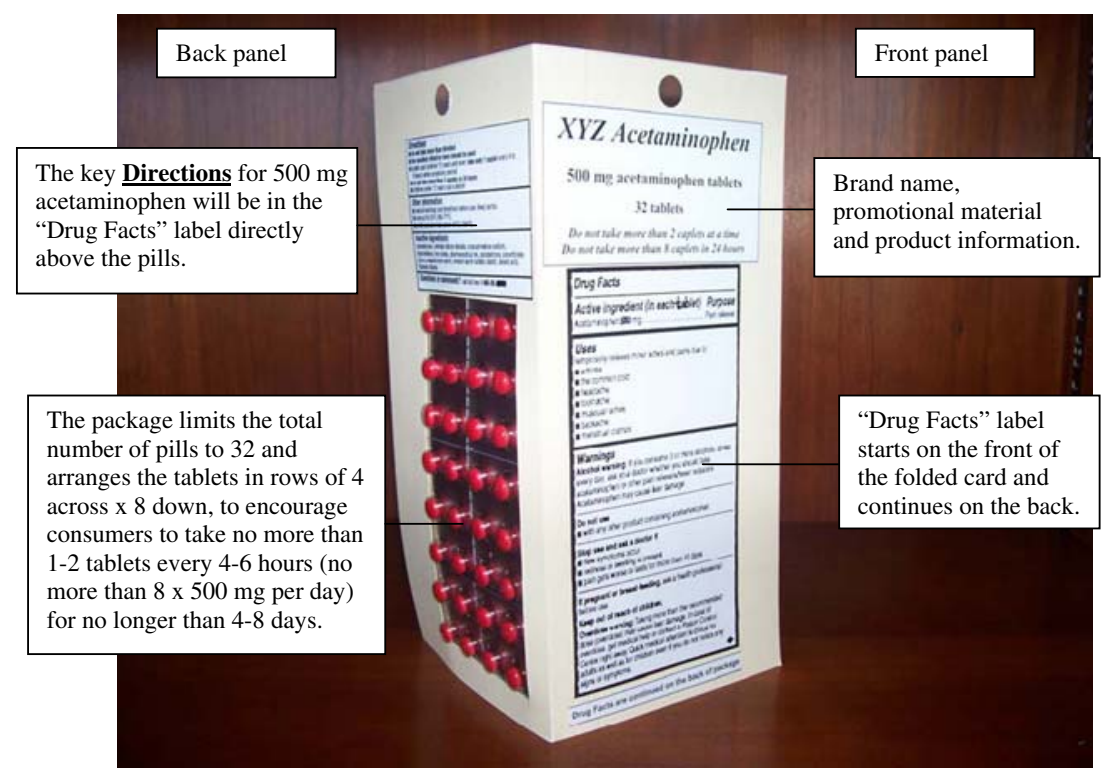

itself, rather than on the outer carton or in package inserts, increases the likelihood of a user noticing and reading the warning (Barlow and Wogalter 1991; Wogalter et al. 1993, 1996) and complying with it (Wogalter and Young 1994).

Larger print size Increasing the surface area on product containers to accommodate additional or larger labeling (for example, by using supplemental cap labels or attaching supplemental information tabs to bottles) has been shown to significantly facilitate the communication of instructions and warnings, not least because it enables the use of larger print size, which is especially important to elderly consumers and those with visual impairments (Barlow and Wogalter 1991;
Wogalter et al. 1993; Wogalter and Dietrich 1995; Wogalter et al. 1996, 1999).

FDA regulations stipulate a minimum font size of 6 . However, Sheedy et al. (2005) found that optimal legibility was attained at 10-point font size; Wogalter and Vigilante (2003) found the optimal size to be between 7-11; Watanabe et al. (1994) concluded that in order to enhance readability for the elderly, OTC drug labeling should use a vertical type size of at least 20/40 RS (6.7 pt) and letter compression of no more than 39 characters per inch.

Conspicuous and explicit Another requirement for successfully conveying warnings and risk information is
Fig. 2 The inside panels of the prototype compliance packaging

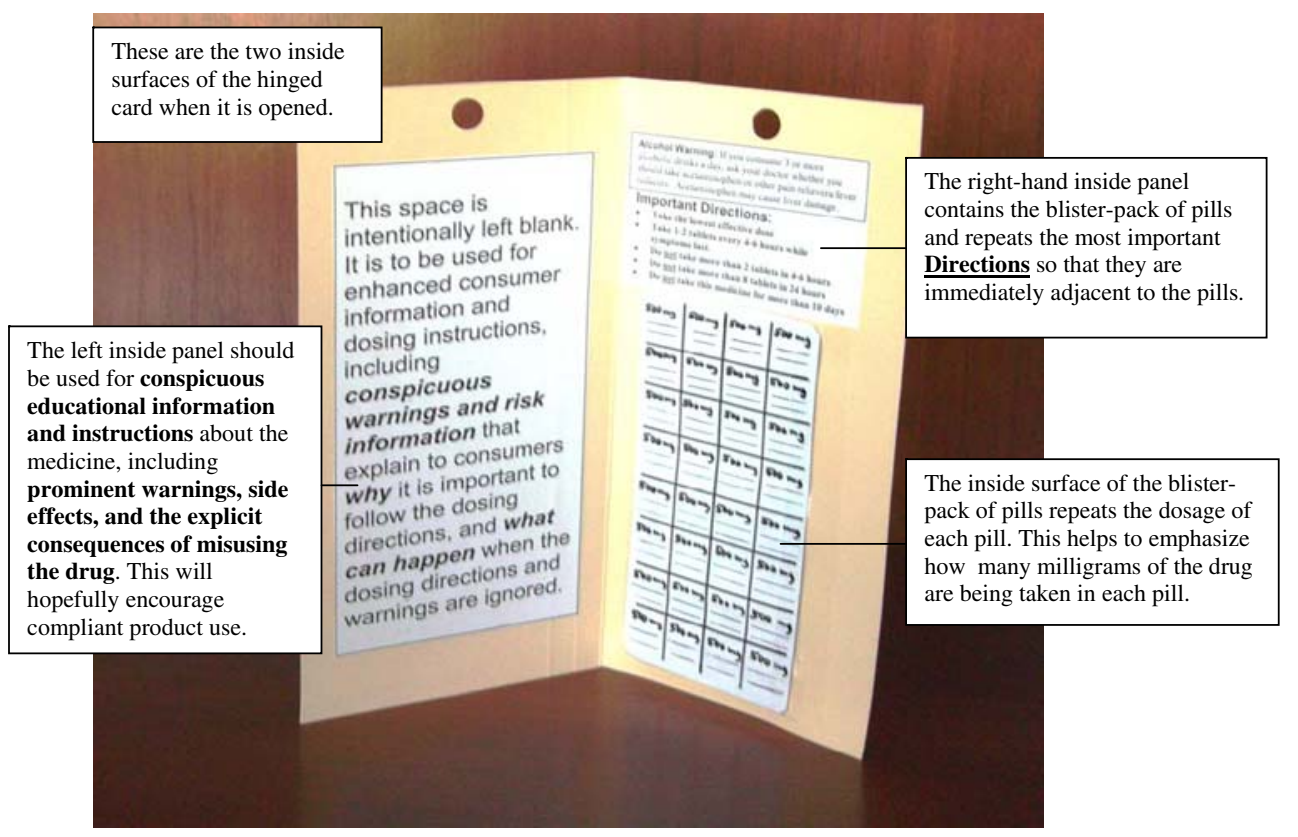


that the message (the words themselves) be conspicuous and explicit. Research indicates that the use of certain signal words, color, spacing, letter size and highlighting all play important roles in making warnings more prominent, salient and memorable (Braun and Silver 1995; Wogalter et al. 2002). Moreover, Laughery and Stanush (1989) have shown that people are far more likely to heed a warning when the information is explicit and gives examples of the consequences of ignoring the warning (rather than just generalized "do not..." types of warnings).

These important principles of effective risk communication have been confirmed by numerous studies (cf. Wogalter 2006), including research directly concerning acetaminophen warnings. Cheatham and Wogalter (2003) compared the effectiveness of composite existing acetaminophen product labels with a revised label that provided more explicit text about the dangers of concomitant alcohol and acetaminophen use, and incorporated several proven characteristics of warning design enhancement. Results indicated that significantly more respondents who were exposed to the revised label $(70 \%)$ rather than the composite existing labels (41\%) were knowledgeable about the acetaminophen/alcohol combination hazard.

Kalsher and Wogalter (2002) found that 92\% of respondents indicated they wanted to be informed about the organ-specific risks of OTC analgesics, and $73.3 \%$ indicated they would take a smaller dose if they were aware of the organ-specific risks associated with OTC analgesics. Also, 33\% said they would consult a doctor before using OTC analgesics and 30\% said they might decide not to use the products if they were provided with information about the organ-specific risks.

\section{Industry considerations for compliance packaging}

Manufacturing and environmental costs Manufacturers may be hesitant to adopt alternative packaging and labeling designs because of increased costs. Although re-tooling the production line is initially expensive, the production costs diminish over time. As for the environment, the blister packing might be made with bio-degradable material rather than regular plastic, and the prototype uses only marginally more paper for the card arrangement than would be used, in total surface area, for a carton. Shelf space is another consideration. The flattened design of the prototype makes it less bulky than a bottle, or even a carton, and the prototype can be displayed on hanging pegs (rather than a shelf), which is also space-saving.

Regulation Another consideration for OTC drugs is that the packaging must comply with the Poison Prevention
Packaging Act (PPPA), ${ }^{5}$ administered and enforced by the US Consumer Product Safety Commission. This regulation dictates the types of unit packaging that can be used for different drug products. For example, blister packs of acetaminophen $(500 \mathrm{mg})$ must be child resistant to 3 units; ibuprofen $(200 \mathrm{mg})$ must be child resistant to 5 units.

\section{Conclusion}

Ultimately, safety benefits to consumers will hopefully balance any additional costs. This compliance packaging offers a relatively inexpensive, practical method to increase the likelihood that the OTC drug warnings and dosing directions will be noticed, read and complied with. It may help to: (1) make it more difficult for consumers to simply "pop" a handful of pills; (2) make it pro-forma for consumers to see the warnings and dosing directions each and every time they use the product; (3) make consumers aware of the organ-specific risks and consequences of exceeding the dosing directions; (4) make it easier for consumers to keep track of the number of pills they consume per dose and per day.

Disclosure The author holds a provisional patent on the prototype compliance packaging described in this review article.

Disclaimer The views expressed herein are the author's alone and do not represent the views of the United States government or any agency thereof.

Open Access This article is distributed under the terms of the Creative Commons Attribution Noncommercial License which permits any noncommercial use, distribution, and reproduction in any medium, provided the original author(s) and source are credited.

\section{References}

Abbott FV, Fraser MI (1998) Use and abuse of over-the-counter analgesic agents. J Psychiatry Neurosci 23(1):13-34

Amar PJ, Schiff ER (2007) Acetaminophen safety and hepatoxicitywhere do we go from here? Expert Opin Drug Saf 6(4):341-355

American Gastroenterological Association news release, March 19, 1998, reporting results of the Roper Starch Worldwide survey about US use of non-steroidal anti-inflammatory drugs. http:// www.gastro.org/wmspage.cfm?parm1=398, accessed 5/18/08

Barlow T, Wogalter MS (1991) Increasing the surface area on small product containers to facilitate communication of label information on warnings. Proceedings of Interface. Human Factors Society, Santa Monica, CA, 7:88-93

\footnotetext{
$\overline{{ }^{5} \text { See } 16 \text { CFR }}$ 1700. The substances are listed at 16 CFR 1700.14, the standards are at $16 \mathrm{CFR} 1700.15$, and the test methods are at $16 \mathrm{CFR}$ 1700.20 .
} 
Bateman DN, Gorman DR, Bain M, Inglis JH, House FR, Murphy D (2006) Legislation restricting paracetamol sales and patterns of self-harm and death from paracetamol-containing preparations in Scotland. Br J Clin Pharmacol 62(5):573-581 Nov

Bolesta S, Haber SL (2002) Hepatoxicity associated with chronic acetaminophen administration in patients without risk factors. Ann Pharmacother 36:331-333

Bond GR, Novak JE (1995) The human and economic cost of paracetamol (acetaminophen) overdose. Pharmaco Economics 8 (3):177-181

Bonkovsky HL, Kane RE, Jones DP et al (1994) Acute hepatic and renal toxicity from low doses of acetaminophen in the absence of alcohol abuse or malnutrition: evidence for increased susceptibility to drug toxicity due to cardiopulmonary and renal insufficiency. Hepatology 19(5):1141-1148

Bower WA, Johns M, Margolis HS, Williams IT, Bell BP (2007) Population-based surveillance for acute liver failure. Am J Gastroenterol 102:2459-2463

Braun CC, Silver NC (1995) Interaction of signal word and colour on warning labels: differences in perceived hazard and behavioural compliance. Ergonomics 38(11):2207-2220

Chan TYK (2000) Improvements in the packaging of drugs and chemicals may reduce the likelihood of severe intentional poisonings in adults. Human Exp Toxicol 19(7):387-391 Jul

Cheatham DB, Wogalter MS (2002) Reported likelihood of reading over-the-counter (OTC) medication labeling and contacting a physician. Proceedings of the Human Factors and Ergonomics Society 46th Annual Meeting 1452-1456

Cheatham DB, Wogalter MS (2003) Comprehension of overthecounter drug label warnings concerning consumption of acetaminophen. Proceedings of the Human Factors and Ergonomics Society 47th Annual Meeting 1540-1544

Consumer Healthcare Products Association, Executive Newsletter, September 27, 2002. http://www.chpa-info.org/Web/newsletter/ archive/2002/9_27_02_xnl.html\#1 accessed 5/18/08

Dart RC (2001) The use and effect of analgesics in patients who regularly drink alcohol. Am J Manag Care 7(19 Suppl):S597-601 Dec

Donohoe E, Walsh N, Tracey JA (2006) Pack-size legislation reduces severity of paracetamol overdoses in Ireland. Ir J Med Sci 175 (3):40-42 Jul-Sep

Downie A, Ali A, Bell D (1993) Severe metabolic acidosis complicating massive ibuprofen overdose. Postgrad Med J 69 (813):575-577 Jul

Eriksson LS, Broome U, Kalin M et al (1992) Hepatoxicity due to repeated intake of low doeses of paracetamol. J Intern Med 231 (5):567-570

Federal Register, December 26, 2006; 71(247):77317-77352

Francis S-A, Barnett N, Denham M (2005) Switching of prescription drugs to over-the-counter status. Is it a good thing for the elderly? Drugs Aging 22(5):361-370

Greene SL, Dargan PI, Leman P, Jones AL (2006) Paracetamol availability and recent changes in paracetamol poisoning: is the 1998 legislation limiting availability of paracetamol being followed? Postgrad Med J 82(970):520-523 Aug

Gyamlani GG, Parikh CR (2002) Acetaminophen toxicity: Suicidal versus accidental. Critical Care 6:155-159

Hall AK, Curry C (1994) Changing epidemiology and management of deliberate self poisoning in Christchurch. N Z Med J 107:396-399

Halpern SM, Fitzpatrick R, Volans GN (1993) Ibuprofen toxicity. A review of adverse reactions and overdose. Adverse Drug React Toxicol Rev 12(2):107-128 Summer

Hawkins LC, Edwards JN, Dargan PI (2007) Impact of restricting paracetamol pack sizes on paracetamol poisoning in the United Kingdom. A review of the literature. Drug Safety 30(6):465-479

Hawton K, Ware C, Mistry H, Hewitt J, Kingsbury S, Roberts D, Weitzel H (1995) Why patients choose paracetamol for self poisoning and their knowledge of its dangers. BMJ 310 (6973):164-168

Hawton K, Ware C, Mistry H, Hewitt J, Kingsbury S, Roberts D, Weitzel H (1996) Paracetamol self-poisoning: Characteristics, prevention and harm reduction. Br J Psychiatry 168:43-48 Jan

Hawton K, Townsend E, Deeks J, Appleby L, Gunnell D, Bennewith O, Cooper J (2001) Effects of legislation restricting pack sizes of paracetamol and salicylates on self poisoning in the United Kingdom: before and after study. Br Med J 322(7296):12031207 May 19

Hawton K, Simkin S, Deeks J, Cooper J, Johnston A, Waters K, Arundel M, Bernal W, Gunson B, Hudson M, Suri D, Simpson K (2004) UK legislation on analgesic packs: before and after study of long term effect on poisonings. BMJ 329:1076-1083 November 6

Huott MA, Storrow AB (1997) A survey of adolescents' knowledge regarding toxicity of over-the-counter medications. Acad Emerg Med 4:214-218

Jowett NI (2004) Paracetamol restriction has not reduced deaths from suicide or emergency medicine work-load. Rapid Responses for Hawton et al. http://www.bmj.com/cgi/eletters/329/7474/1076

Kalsher MJ, Wogalter MS (2002) Over-the-counter analgesics: A survey of the public's knowledge, attitudes and beliefs regarding current labeling practices. Proceedings of the Human Factors and Ergonomics Society 46th Annual Meeting 1735-1738

Kim J, Gazarian M, Verjee Z, Johnson D (1995) Acute renal insufficiency in ibuprofen overdose. Pediatr Emerg Care 11 (2):107-108 Apr

Kurtovic J, Riordan SM (2003) Paracetamol-induced hepatoxicity at recommended dosage. J Int Med 253:240-243

Larson AM (2007) Acetaminophen hepatoxicity. Clin Liver Dis 11 (3):525-548 Aug

Laughery KR, Stanush JA (1989) The effects of warning explicitness on product perceptions. Proc Hum Factors Ergon Soc 33:431435

Le HT, Bosse GM, Tsai Y (1994) Ibuprofen overdose complicated by renal failure, adult respiratory distress syndrome, and metabolic acidosis. J Toxicol Clin Toxicol 32(3):315-320

Lee WM (2004) Acetaminophen and the US Acute Liver Failure Study Group: lowering the risks of hepatic failure. Hepatology 40 (1):6-9

Lesch in MF (2006) Consumer product warnings: research and recommendations. In: Wogalter MS (ed) Handbook of Warnings, Chapter 10. Lawrence Erlbaum Associates

Moling O, Cairon E, Rimenti G et al (2006) Severe hepatoxicity after therapeutic doses of acetaminophen. Clin Ther 28(5):755-760

Moore TJ, Cohen MR, Furberg CD (2007) Serious adverse drug events reported to the Food and Drug Administration, 19982005. Arch Intern Med 167(16):1752-1759 September 10

Morgan O, Griffiths C, Majeed A (2005) Impact of paracetamol pack size restrictions on poisoning from paracetamol in England and Wales: an observational study. J Publ Health (Oxford, England) 27(1):19-24 Mar

Myers RP, Li B, Shaheen AA (2007) Emergency department visits for acetaminophen overdose: a Candadian population-based epidemiologic study (1997-2002). CJEM 9(4):267-274 Jul

Myers WC, Otto TA, Harris E, Diaco D, Moreno A (1992) Acetaminphen overdose as a suicidal gesture: a survey of adolescents' knowledge of its potential for toxicity. J Am Acad Child Adolesc Psychiatry 31(4):686-690 Jul

Nabors LA, Lehmkuhl HD, Parkins IS, Drury AM (2004) Reading about over-the-counter medications. Issues Compr Pediatr Nurs 27(4):297-305

National Consumers League 2003. Over-the-Counter Pain Medication Study. http://www.nclnet.org/otcpain/jan30release.htm and http:// www.nclnet.org/otcpain/release.htm accessed 5/18/08 
Nourjah P, Ahmad SR, Karwoski C, Willy M (2006) Estimates of Acetaminophen (Paracetamol)-associated overdoses in the United States. Pharmacoepidemiol Drug Saf 15:398-405

Ostapowicz G, Fontana RJ, Schiodt FV, Larson A, Davern TJ, Han SHB et al (2002) US Acute Liver Failure Study Group. Results of a prospective study of acute liver failure at 17 tertiary care centers in the United States. Ann Intern Med 137(12):947-954

Papadopoulos FC (2004). UK legislation on analgesic packs: does the decline in poisonings reflect reduction in overall suicide deaths? Rapid Responses for Hawton et al. 329(7474) 1076 at http:// www.bmj.com/cgi/eletters/329/7474/1076

Prince MI, Thomas SHL, James OFW, Hudson M (2000) Reduction in incidence of severe paracetamol poisoning. The Lancet 355:2047-2048 June 10

Schiodt FV, Rochling FA, Casey DL, Lee WM (1997) Acetaminophen toxicity in an urban county hospital. N Engl J Med 337 (16):1112-1117 October 16

Sheedy JE, Subbaram MV, Zimmerman AB, Hayes JR (2005) Text legibility and the letter superiority effect. Hum Factors 47 (4):797-815

Sheen CL, Dillon JF, Bateman DN, Simpson KJ, MacDonald TM (2002) Paracetamol pack size restriction: the impact on paracetamol poisoning and the over-the-counter supply of paracetamol, aspirin and ibuprofen. Pharmacoepidemioly and Drug Safety 11(4):329-331 Jun

Silver NC, Braun CC (1993) Perceived readability of warning labels with varied font sizes and styles. Saf Sci 16:615-625

Stumpf JL, Skyles AJ, Alaniz C, Erickson SR (2007) Knowledge of appropriate acetaminophen doses and potential toxicities in an adult clinic population. Journal of the American Pharmacists Association 47(1):35-41 Jan/Feb

Turvill JL, Burroughs AK, Moore KP (2000) Change in occurrence of paracetamol overdose in UK after introduction of blister packs. The Lancet 355(9220):2048-2049 June 10

US Food and Drug Administration. "Use CautionWith Pain Relievers." FDA Consumer Magazine, January-February 2003, Pub No. FDA05-1331C, revised September 2005. http://www.fda.gov/ fdac/features/2003/103_pain.html, accessed 5/18/08

US Food and Drug Administration. "Safe Use of Over-the-Counter Pain Relievers (analgesics) and Fever Reducers (antipyretics). http://www.fda.gov/cder/drug/analgesics/default.htm, accessed 5/ $18 / 08$

Volans G, Monaghan J, Colbridge M (2003) Ibuprofen overdose. Int J Clin Pract Suppl (135):54-60. Apr

Watanabe RK, Gilbreath MK, Sakamoto CC (1994) The ability of the geriatric population to read labels on over-the-counter medication containers. J Am Optom Assoc 65(1):32-37
Watson WA, Litovitz TL, Rodgers GC Jr et al (2005) 2004 annual report of the American Association of Poison Control Centers toxic exposure surveillance system. Am J Emerg Med 23(5):589 666

Wazaify M, Shields E, Hughes CM, McElnay JC (2005) Societal perspectives on over-the-counter (OTC) medicines. Fam Pract 22 (2):170-176 Apr

WebMed Pain Management Health Center. Article link: http://www. webmd.com/pain-management/news/20030130/when-relievingpain-raises-risk. Press release dated Jan. 30, 2003

Wilcox CM, Cryer B, Triadafilopoulos G (2005) Patterns of use and public perceptions of over-the-counter pain relievers: Focus on nonsteroidal anti-inflammatory drugs. J Rheumatol 32(11):2218 2224 Nov

Winkler E, Halkin H (1992) Paracetamol overdose in Israel. Isr J Med Sci $28: 811-812$

Wogalter MS (ed) (2006) Handbook of warnings. Lawrence Erlbaum Associates, Mahwah, NJ

Wogalter MS, Dietrich DA (1995) Enhancing label readability for over-the-counter pharmaceuticals by elderly consumers. Proceedings of the Human Factors and Ergonomics Society 39th Annual Meeting. Santa Monica, CA, 143-147

Wogalter MS, Vigilante WJ (2003) Effects of label format on knowledge acquisition and perceived readability by younger and older adults. Ergonomics 46(4):327-344 Mar 15

Wogalter MS, Young SL (1994) The effect of alternative product-label design on warning compliance. Appl Ergon 25(1):53-57

Wogalter MS, Forbes RM, Barlow T (1993) Alternative product label designs: Increasing the surface area and print size. Proceedings of Interface. Human Factors Society, Santa Monica, CA, 8:181-186

Wogalter MS, Magurno AB, Scott KL, Dietrich DA (1996) Facilitating information acquisition for over-the-counter drugs using supplemental labels. Proceedings of the Human Factors and Ergonomics Society 40th Annual Meeting. Santa Monica, CA, 732-736

Wogalter MS, Magurno AB, Dietrich DA, Scott KL (1999) Enhancing information acquisition for over-the-counter medications by making better use of container surface space. Exp Aging Res 25:27-48

Wogalter MS, Conzola VC, Smith-Jackson TL (2002) Research-based guidelines for warning design and evaluation. Appl Ergon 33:219-230

Wood DM, Monaghan J, Streete P, Jones AL, Dargan PI (2006) Fatality after deliberate ingestion of sustained-release ibuprofen: a case report. Crit Care 10(2):R44

Zuckerman GB, Uy CC (1995) Shock, metabolic acidosis, and coma following ibuprofen overdose in a child. Ann Pharmacother 29 (9):869-871 Sep 